\author{
Marquette University \\ e-Publications@Marquette
}

$5-2020$

\title{
Using Online Discussions to Connect Theory and Practice in Core Engineering Undergraduate Courses
}

\author{
Lisa B. Bosman \\ Purdue University \\ Somesh Roy \\ Marquette University, somesh.roy@marquette.edu \\ Walter M. McDonald \\ Marquette University, walter.mcdonald@marquette.edu \\ Cristinel Ababei \\ Marquette University, cristinel.ababei@marquette.edu
}

Follow this and additional works at: https://epublications.marquette.edu/electric_fac

Part of the Computer Engineering Commons, and the Electrical and Computer Engineering Commons

\section{Recommended Citation}

Bosman, Lisa B.; Roy, Somesh; McDonald, Walter M.; and Ababei, Cristinel, "Using Online Discussions to Connect Theory and Practice in Core Engineering Undergraduate Courses" (2020). Electrical and Computer Engineering Faculty Research and Publications. 645.

https://epublications.marquette.edu/electric_fac/645 


\title{
Using Online Discussions to Connect Theory and Practice in Core Engineering Undergraduate Courses
}

\author{
Lisa Bosman, PhD* \\ Purdue University \\ Purdue Polytechnic Institute \\ West Lafayette, IN, USA \\ Somesh Roy, PhD \\ Marquette University \\ Opus College of Engineering \\ Milwaukee, WI, USA \\ Walter McDonald, PhD \\ Marquette University \\ Opus College of Engineering \\ Milwaukee, WI, USA \\ Cristinel Ababei, PhD \\ Marquette University \\ Opus College of Engineering \\ Milwaukee, WI, USA
}

*Corresponding Author: Lisa Bosman, PhD (lbosman@purdue.edu), Purdue University, Purdue Polytechnic Institute, 610 Purdue Mall, West Lafayette, IN 47907

\begin{abstract}
Providing engineering undergraduate students opportunities to connect real-world applications with theory is key to preparing them for the workforce; however, this task often requires a balancing act between meeting course objectives in content-heavy core engineering undergraduate courses and providing experiences that connect real-world applications with theory. This study seeks to address this problem through the integration of online discussion prompts to promote a connection to real-world practical applications. The study included undergraduate students enrolled in three engineering core courses. The hypothesis was that participation in online discussions (using prompts) would lead to 1) an increase in student empowerment towards selfregulated learning and 2) enhanced student engagement and perception of participating in online discussions. Students participated in eight online discussions and were evaluated using pre- and post-assessments. Findings show students across disciplines liked online discussions because they allowed enough time to develop thoughts and promoted critical thinking through extending class topics, which increased the control of their own learning. In addition, students were more active in the course activities and offered useful feedback and reflection, which enhanced student engagement. Such feedback included ideas to improve the online discussion, for example, the need for clearer instructions and instructor feedback, better scheduling of due dates, and more engaging discussion prompts. In summary, integrating online discussions into core engineering courses, without sacrificing class content, can indeed have positive implications towards self-regulated learning and higher student engagement.
\end{abstract}


Key Words: Online discussions, Self-regulated learning, Student engagement, Undergraduate, Writing, Information literacy

\section{Introduction}

Engineering undergraduate students thrive on opportunities to connect real-world applications with theory [1, 2], which is key to preparing them for the workforce. However, limited resources are available for engineering faculty who seek to offer legitimate active learning experiences while balancing course objectives in content-heavy core engineering undergraduate courses and engaging learning experiences [3]. This study seeks to address this problem through the integration of online discussion prompts to promote a connection between course content and real-world practical applications [4].

\subsection{Problem Identification}

Engineering undergraduate curriculum includes general courses typically required of all engineering majors such as Statics, Thermodynamics, Linear Systems, etc., as well as mandatory discipline-specific "core courses" required of that particular engineering discipline. For example, typically, civil engineering students take a course on Water Resources Planning and Management, electrical and computer engineering students take a course on Embedded Systems Design, and mechanical engineering students take a course on Fundamentals of Heat Transfer. For engineering faculty who teach these "core courses," there is often difficulty in contriving a balance between the amount of theoretical, analytical, and rigorous content and integration of real-world, authentic applications [5, 6]. According to Ambrose and colleagues (2010), if students do not see practical value in the assignments in a course, they become less motivated [7]. This can result in a concept well-known in engineering as weed-out courses (intentionally difficult courses to separate the high achievers from less prepared students), where a student's lack of motivation could result in a bad or failing grade that then causes them to leave school or transfer to a different major [8, 9]. Weedout courses are a significant problem across all areas of engineering as nation-wide retention rates for students that obtain an engineering within 6 years remains below 60\% [10]. Additionally, while a lack of real-world authentic applications may hinder student motivation, students in engineering also suffer from limited writing and communication experiences. It has been shown that integration of a writing component in core engineering courses helps learning, communication skills, and future employability $[11,12]$. However, integration of such a component can be effort- and timeintensive for the instructor [13] and introduces difficulties in evaluation [14]. Writing assignments can also feel disconnected and challenging for students [15, 16]. Therefore, in core engineering courses there is a clear need to (1) improve student motivation through activities that demonstrate the practical value of the learning material, and (2) implement writing assignments at a low effort to the instructor that improve student learning.

\subsection{Current Approaches to the Problem}

In response to this dilemma, engineering programs and faculty commonly follow one of three paths. First, there is a trend of leveraging authentic learning into the freshman first-year experience class and capstone coursework, which also involve technical writing in some form. In the latter, industry-sponsored projects are readily used for senior-level engineering students to demonstrate 
their preparedness for entering the workplace. These offer great opportunities for students to gain real-world experience. But in a recent survey, students indicated they wanted more courses to focus on the connections between real-world applications and theory [12]. Second, in some cases, labs are added to coursework to promote active and applied learning as well as report-writing. If a lab is connected to the course, instructors can decide to focus more time on real-world projects instead of conducting traditional lab experiments. But this is frequently frowned upon as many core courses are foundational in that they prepare students for taking more advanced coursework. As an additional deterrent, lab courses are often led by a Graduate Teaching Assistant, who are often more concerned with teaching from a theoretical-mathematical perspective and less focused on connecting the topic to real-world settings. Third, in the case that a lab is not offered, engineering faculty typically focus the entirety of the course on quantitative problem solving and may add in an application-focused project due at the end of the course.

Thus, there are rather limited opportunities for students to learn and create connections between real-world applications and the theoretical concepts taught during the course and practice their writing/communication skills. As a result, it is not uncommon for these "core courses" to focus more on rigor to gain foundational knowledge at the expense of a more authentic learning that would really emphasize the connection with the practical real-world.

\subsection{Proposed Solution and Motivation}

In this work, the proposed solution to connect theory with real-world applications through a writing assignment is the integration of online discussions into the course activities. This high return and low effort complement to the face-to-face in-class interaction requires limited classroom time from the faculty. Therefore, the faculty can continue to optimize rigor and analytical problem solving within the lecture learning environment. At the same time, the proposed approach leverages the asynchronous nature of an online environment to promote curiosity in connecting practical realworld scenarios to the theoretical. This makes way for introducing blended learning [26] in the conventional classroom structure. Additionally, online discussions require composing posts and replies that will be read by peers. Therefore, a writing component is inherent in this solution.

This paper aims to address two research questions as follows:

- RQ 1: How can online discussions be used to increase student empowerment towards selfregulated learning in undergraduate core engineering courses?

- RQ 2: How can online discussions increase student engagement and enhance student perceptions of class participation?

The next section provides a brief literature review on blended learning and integrating writing into the engineering discipline to better understand the challenges, recommendations, and benefits of these approaches. Section three gives an overview of the methods for the analysis and a brief description of the online discussions into three common engineering core courses (Civil Engineering - Water Resources Planning and Management, Electrical and Computer Engineering

- Embedded Systems Design, and Mechanical Engineering Course - Fundamentals of Heat Transfer). In addition, this section showcases the survey instrument used to assess the research questions. Section four highlights the results, applying both a qualitative and quantitative 
perspective of data analysis. A brief discussion related to the research questions is then presented in Section five. Finally, Section six concludes with a summary and recommendations for future research.

\section{Background and Literature Review}

Participating in online discussions, as a form of writing and a means of blended learning, has been shown to promote curiosity, encourage critical thinking, and enhance information literacy. The literature is rich with examples where writing has been integrated into coursework, particularly engineering courses. This section provides an overview of recent findings and approaches to both blended learning and the integration of writing into engineering coursework.

\subsection{Benefits of Integrating Writing into Engineering Coursework}

Integrating writing into core engineering coursework is not new. The benefits of a writingintensive curriculum have been explored by several researchers in different contexts. Relevant research shows that inclusion of a writing component increases student perceived employability and career development skills. For example, in a study involving chemical engineering students, Cherrstrom and colleagues [17] required students to submit reflections (using guided prompts), iterate on writing samples using instructor feedback, and develop a portfolio. The pre- and postsurveys found student participants perceived improvement in learning and identified the skills as beneficial for future employability. Linsdell and Anagnos [11] redesigned and evaluated a technical communication course aimed to assist engineering students with developing transferrable career skills. The instructors were intentional to incorporate best writing practices, continuous instructor feedback, and critical thinking into the assignments. The evaluation found an increase in positive attitudes towards technical communication skill development. Both Cherrstrom et al. [17] and Linsdell and Anagnos [11] also noted evidence towards increases in student learning outcomes. In particular, appropriate intervention or feedback was often found to be instrumental in improvement of students' learning outcomes [18-20].

Integration of writing into engineering course work can also improve student learning. Fernandes [18] analyzed the writing performance of engineering students, where one group of students received an intervention of additional teaching focus on grammar rules and the other group of students did not. Both groups of students were required to complete weekly assignments and were provided immediate feedback. The instructor found that the student group who received the initial intervention consistently outperformed the control group. Fries and colleagues [19] reported improvements in student learning outcomes related to professional issues, problem-solving skills, and both oral and written communication competencies (e.g., spelling and grammar, and logical flow of content) when students were required to work with a mentor to complete a written research assignment integrating one specialization in civil engineering. Calvo and Ellis [20] performed qualitative analysis of student interviews and demonstrated close associations between the various types of feedback and improved academic performance in a writing-intensive course. They used an engineering course which required students to work in teams of two to write a project proposal for an e-business. Students were provided an initial writing workshop, offered regular feedback from a writing tutor, provided feedback from an automated system (Glosser), and participated in peer review activities. Vasquez and colleagues [21] also found that writing activities improved the 
students' ability to build explanations and argumentation. They incorporated "writing to teach" activities in a second-year introductory physical chemistry course. In addition, they also reported that students developed a greater understanding of quantum mechanics applications and their importance due to the writing assignments.

In summary, the key benefits of intentional incorporation of writing and appropriate feedback mechanisms into core engineering coursework have been explored in the literature. These benefits include improved student learning outcomes, increased student perceptions of workforce preparation, student satisfaction, and a better understanding of subject matter applications.

\subsection{Challenges of Integrating Writing into Engineering Coursework}

Along with the benefits, there are many challenges with including writing assignments in engineering coursework. Key challenges include a lack of engagement and a perceived disconnect between the technical content and writing assignments [14, 15, 22], time and effort management $[13,15]$, difficulties in assessment and evaluation of student's performance [13, 16, 23], and technological difficulties [13, 16], etc. For example, Vetter and Nunes [22] designed and deployed a writing component specifically for engineering majors using concepts including genre theory and social knowledge to aid students in writing essays, conducting peer reviews, and creating a portfolio. They noted two key challenges, including lack of engagement and difficulty in conveying the importance of skill development for future employment. In another study, Naqvi [14] reported that students favored analytical skill development or qualitative knowledge attainment over writing and literature synthesis, and saw a little value in the writing components in the coursework. This case study was done based on an English course offered to only engineering students and involved questionnaires, focus groups, interviews, and assignment reports. In general, the engineering students found information literacy and literature synthesis to be challenging [14]. Additionally, Patterson and Slinger-Friedman [13] also pointed out the pressures related to promotion and tenure (which do not support investing lots of time into quality teaching) can become a challenge for such course design.

Writing assignments in online or blended environments face similar challenges. Katz and Thoren [15] used Wiki-based projects in a lecture-based calculus course and found that the project design left students responsible for only a minor, specific portion of the website, resulting in a disconnected, lack of belonging throughout the project. Although they found that the Wiki-based project was an overall positive experience for the students. While the reported benefits were positive, Katz and Thoren [15], Miyazoe and Anderson [16], and Patterson and Slinger-Friedman [13] found time management for instructors, both for upkeeping of the Wiki technology and evaluation, a major challenge. In their study, Miyazoe and Anderson [16] used Wiki technology but in a blended learning approach by integrating online writing activities. On the other hand, Patterson and Slinger-Friedman [13] assessed the incorporation of writing into introductory geography classes, where activities included developing note cards to enable critical thinking, a course wiki page, pre-writing exercises for geography research papers and essays to assess the application of knowledge. Both these studies also reported challenges with evaluating collaborative student work and difficulty in designing the assignments. Duchardt and colleagues [23] also evaluated the integration of writing into three courses taught strictly online by analyzing writing samples and found the majority of students did not demonstrate mastery in sentence formation, specifically, in complicated sentence constructions and punctuations. 
In summary, key challenges related to incorporating writing into engineering coursework have been found related to student engagement, conveying value, instructor's time, assessing team projects, and obtaining student learning outcomes.

\subsection{Recommendations for Integrating Writing into Engineering Coursework}

To overcome some of the challenges presented in the previous section, the literature offers recommendations to promote positive experiences with integrating writing into core engineering coursework. These recommendations include promoting student awareness [24], utilizing peerreview [25, 26], and rubric-based approach to evaluation [26, 27]. In their study, Idrus and authors [24] were intentional to incorporate lifelong learning skills in the assignments that involved outlining an article, writing a technical project report, and writing a business proposal. Their study was done based on a technical writing course for engineering students at private engineering and technology-based university. The authors recommended that promoting student awareness of how an assignment relates to their career and lifelong learning would result in increased motivation. Yakhno and Ekin [25] emphasized the positive effects of peer-review in implementing writingbased assignments. They made improvements to the design of a technical writing course for computer engineering students which incorporated a project-based learning pedagogical approach. Students were required to assist in the organization of a technical conference, write and present a research paper at the conference, and participate in the conference preparations as a peer reviewer. Peer-review and feedback as a key to student success was also highlighted by Leydon and colleagues [26] who integrated a writing project into a first-year introductory geography course. Their analysis of student grades demonstrated improvements in student writing and geographical understanding over the course period due to peer feedback process. They also cite the use of criterion-based rubrics as an important tool. Bonham and authors [27] also recommended using a course rubric to emulate the characteristics of writing qualities. They used the course rubrics with a scaffolded writing assignment within a first-semester calculus-based laboratory course. The students were asked to grade an example good- and poor-quality report using the course rubric. As a result of the student surveys and artifact assessment, Bonham and authors [27] recommend the use of scaffolded writing assignments, including continuous practice and feedback, for other instructors implementing writing into the engineering curriculum.

In summary, there are several examples available in the literature that highlight the ways in which stand-alone technical writing courses or writing assignments in core engineering courses can be effectively used to increase student motivation and improve overall writing skills. However, these approaches require significant instructor and classroom time dedicated to course design that involves appropriate planning for assignment evaluation and feedback mechanisms. As pointed out in Sec 2.2, time required for such planning may be a challenge in core engineering courses. Therefore, new and innovative methods are needed to incorporate writing assignments into engineering courses that can overcome many of the challenges identified in literature.

\subsection{Blended Learning as an Approach to Improve Learning Experience}

Blended learning is an approach that can overcome these challenges through a combination of online and face-to-face interactions to promote learning [28-30]. Blended learning is a relatively new concept that gained popularity in pedagogical research in the 2000s [31-33]. The advances of 
the Internet, computer literacy, and distance-learning paradigms have led to a quick rise in the popularity of blended learning approaches. In a blended learning classroom, the student enrolled in a course with face-to-face structured instructions has some control over the time, pace, and location of learning through online tools. This is different than conventional technology-rich education approaches such as competency-based learning or other types of courses that are offered completely online [34]. According to a U.S. Department of Education report, in 2008 nearly half of all higher education institutions offered blended learning classes [35]. Being a relatively new approach in an increasingly diverse educational environment, the literature on blended learning its benefits, efficacies, challenges, and recommended strategies - are still evolving [34].

Early studies revealed that integrating an online component in a leadership-development program led to an increase in teamwork, shared understanding of concepts and language, and efficient learning [36]. But at the same time, another study concluded that while blended learning makes the learning experience more enjoyable, face-to-face learning plays a more important role than blended learning [37]. Recent studies have focused more on student perception and efficacy of blended learning approaches. Evidence in the literature suggests that blended learning approaches increase appreciation of course material and analytical skills [29], promote collaborative learning [30], and increase participation, motivation, satisfaction, and subjective knowledge [38-41]. Studies also identified various difficulties associated with an appropriate implementation of blended learning such as lack of immediate feedback and the sense of community [42], lack of clarity of instructions [29], socio-cultural interaction and psychological distance [30, 43], and gender and age disparity [44]. In most studies it has been found that direct classroom interaction is still a very important part of learning [32]. Therefore, semi-autonomous online activities should supplement, rather than replace, traditional classroom interaction for an effective self-regulated learning environment. In fact, blended learning also provides a way to integrate writing in course materials such as writing online Wiki [29, 30] and online forums [45, 46].

In summary, online discussions based on real-world situations can help to overcome the challenges related to integrating writing and practical applications into core engineering coursework. The discussions provide a way to convey value by connecting theoretical engineering topics to realworld scenarios and obtaining peer feedback through the act of discussion and response posts. This also can provide continuous practice when online discussions are required at several points throughout the semester. In addition, assessing and evaluating online discussions using a qualitative approach of student perceptions can offer increased insights into the benefits and best practices (from a student perspective) around designing blended learning activities while keeping student-centered learning approaches in mind.

\section{Methods}

\subsection{Study Design}

The study described in this paper was conducted at a private university located in the Midwest United States with an undergraduate engineering student population of about 1100 students during the 2018-2019 school year. During Fall 2017, a total of three engineering faculty applied and were selected to participate in a faculty professional development training. The selection process gave priority for core discipline specific courses (versus general engineering, introductory engineering, 
or capstone courses, for example), which primarily occur in upper level curriculum. The purpose of the training was to show faculty how to integrate online discussions into engineering courses. The faculty received a stipend as compensation for completing the following tasks:

- August: Participate in a 3-day training

- Fall 2017 Semester: (1) Develop and deploy 8 discussion prompts in the engineering classroom. (2) Collect student participant data to assess the outcomes.

- September: Monthly check-in.

- October: Monthly check-in.

- December/January: Final reporting.

The three engineering courses where the 8 discussion prompts were deployed, and outcomes assessed were as follows:

- Civil Engineering Course (Seniors): Water Resources Planning and Management

o Fall 2017 Course Enrollment $=6$

- Electrical and Computer Engineering Course (Seniors): Embedded Systems Design

o $\quad$ Fall 2017 Course Enrollment $=19$

- Mechanical Engineering Course (Juniors): Fundamentals of Heat Transfer

o $\quad$ Fall 2017 Course Enrollment $=30$

Example online discussions prompts for each course are provided in Appendix A, B, and C. Each course required students to participate in 8 online discussion sessions. The online discussion session was completed outside the classroom using a learning management system. Students were given initial post and response post deadlines, however, the time spent drafting the posts was up to the individual student.

\subsection{Data Collection and Assessment}

In addition to completing regular coursework, all student participants were asked to complete a pre-class survey, participate in eight different online discussion sessions throughout the semester, and complete a post-class survey upon completion of the semester. Together, the three classes had a total enrollment of 55 students. A total of 40 students completed the pre-class survey and 47 students completed the post-class survey. A summary of the survey instrument questions is provided in Table 1. The Institutional Review Board (IRB), which ensures human involved research is conducted in an ethical manner, approved the study with the caveat of required anonymity and de-identification of specific classes. As such, one data collection instrument was used for all three engineering courses mentioned above.

\section{$<<$ INSERT TABLE $1>>$}

\subsection{Data Analysis}

This study primarily followed a qualitative approach using thematic analysis. According to Braun and Clark [47], a thematic analysis is a foundational qualitative method for discovering patterns within the data. It should be conducted using a step by step process. The NVivo 11 qualitative 
analysis software was used to analyze the qualitative open-ended questions. All data documents were imported into NVivo and the researchers read through the documents several times. The researchers first became thoroughly familiar with the data to generate initial codes. Two researchers individually coded and highlighted the documents with the purpose of identifying themes. Upon completion of the independent analysis, the researchers compared their results, read through the documents again, and came to a consensus for developing themes and a coding framework. It is noteworthy to mention that the unit of analysis was the full response to each question. Responses were only considered and coded with respect to that particular question. For example, if Q1 resulted in responses Q1_Response1, Q1_Rresponse2, and Q1_Response3; and Q2 resulted in responses Q2_Response1, Q2_Response2, and Q2_Response3; Q2_Response1 is only considered with respect to the coding designated for Q2 and not for Q1. As a final step, the researchers revised the themes and wrote the report. The researchers debated the strengths and weaknesses between strictly conceptualizing themes without quotes and heavily using quotes to provide readers with evidence. It was decided to merge the two philosophies and meet in the middle. Quotes were drawn from the data to allow readers to make their own judgments on credibility, accuracy, and fairness [48]. In addition, coding of the qualitative data allowed quantification and prioritization of the themes through basic statistical analysis [49].

\section{Results}

The results are shown with respect to the five survey questions and the two research questions will be answered within the discussion section. To better prepare the readers for aligning the results to the discussion section, it is noteworthy to mention the association between the research questions and survey questions, as shown in Table 2.

$<<$ INSERT TABLE $2>>$

\subsection{SQ 1: Identify the top three factors that are most important for student learning and success?}

In general, responses to this open-ended question can be categorized into three types of factors: (1) identification of factors within a student's perceived control, (2) identification of factors outside a student's perceived control, and (3) mixed - factors both within and outside a student's perceived control. All participant responses were coded as one of the three categories for the purpose of conducting a pre- and post-quantitative analysis. The findings are shown in Table 3. Examples of coded quotes are shown below.

$<<$ INSERT TABLE 3>>

Examples of (1) identification of factors within a student's perceived control are as follows:

- "Focus, be motivated, and be accountable for your actions."

- "Time management, studying, and participating."

- "Open to new things, to jump at opportunities, and to pay attention.”

- “Time management, assignment awareness, and ability to utilize resources."

Examples of (2) identification of factors outside a student's perceived control are as follows: 
- “Clear instructions, a classroom environment that welcomes questions and discussions, and projects that require collaboration."

- "Open-minded environment, flexibility on time frame that it takes a student to understand the concepts, and extra and lots of hard examples."

- "Clear and concise assignments and directions for their work. Keeping the notes and lectures interesting and understandable. Holding students working in groups.”

- “1. A devoted, knowledgeable, and helpful teacher. 2. Accessible student resources. 3. A healthy class environment."

Examples of (3) mixed - factors include within and outside a student's perceived control are as follows:

- “1. Student teacher relationship is very important because this is how students learn to act professional with other humans. 2. Being able to use multiple parts of your brain in order to learn the material better. 3. Being able to ask questions.”

- “1) Clean, written and accessible materials and instructions. 2) Plenty of instructor/TA resources and other study aid. 3) Academic time management.”

- “1) Teacher Knowledge 2) Teachers ability to communicate that knowledge 3) Student time and effort on homework.”

- “Availability of knowledge, encouragement, dialogue between teacher and student.”

\subsection{SQ 2: What is your perception of blended learning in comparison to face-to-face learning?}

In general, responses to this open-ended question can be categorized into three types of factors: (1) blended learning is preferred, (2) face-to-face learning is preferred, (3) mixed - there are benefits to both blended learning and face-to-face learning. All participant responses were coded as one of the three categories for the purpose of conducting a pre- and post-quantitative analysis. The findings are shown in Table 4. Examples of coded quotes are shown below.

\section{$<<$ INSERT TABLE 4>>}

Examples of (1) blended learning is preferred are as follows:

- "Blended learning disperses the commitment to engage with the material between the student and professor. The student has more control of their learning status within the class due to the independence of having digital and online engagement. This can allow for a deeper discussion of the course material."

- "I think it is a good method of learning. Sometimes I struggle with a concept early on in the process and it becomes challenging for me to follow for the rest. A way to overcome this is by using office hours, TA's... etc to have them be a resource to guide me through it. Overall, I do like blended learning though.”

- "I think that in blended learning people feel safer behind a screen to mess up and try harder to improve themselves. You have time to react and think about what you want to say rather than just say the first thing that comes to your head in a classroom and hope it is correct."

- "Blended learning makes the individual student think on their own more. Sitting down having to do a discussion post forces a student to analyze what they have been in doing class. Whereas face-to-face, sometimes is only a one-way road.” 
Examples of (2) face-to-face learning is preferred are as follows:

- "I definitely prefer face-to-face learning because its hands on and allows you to actually grasp the concept, and when you have questions they are easier to work through in person."

- "I prefer face to face. I am well adapted to a traditional classroom style and if it were up to me, I would never do online things because I am terrible at motivating myself to do work for any sort of unstructured schedule."

- "I enjoy face to face learning more. Often in assignments online and offline, it is not clear on what the purpose of the assignment is. However in person I can ask the Professor."

- "Blended learning is not as effective as face-to-face learning because when you're face-toface with someone you can pick up on nonverbal cues of communication that can help you better understand things."

Examples of (3) mixed - there are benefits to both blended learning and face-to-face learning are as follows:

- "For most part I prefer face to face learning, since everything becomes clear that way. But that does not mean, I don't want to learn through digital means. I just need the instructions to be clear and concise."

- "I like it for courses where content/curriculum and expectations are open-ended, but not in severely structured courses such as math, physics, or classes like statics/dynamics."

- "Blended learning is good to enforce what was learned in face-to-face learning but should not be the only means of education since it does not sink in as well into my mind electronically."

- "I think online learning is a great way to introduce topics and lead into a face-to-face lecture/discussion. I think coming into class with a general sense of what will be taught/discussed is an effective way of creating a focused and productive environment, and so I believe blended learning to be efficient in that regard. I do not believe online learning can or should ever replace a face-to-face discussion, as it is just too limited to ensure proper understanding of the material.”

\subsection{SQ 3: How might you further your skills/knowledge after this class is over?}

In general, four themes arose to how students might further skill and knowledge development after the class is completed: (1) enrolling in additional engineering coursework, (2) seeking out additional real-world projects, (3) seeking out professional development opportunities, and (4) unsure. All participant responses were coded as one of the four categories for the purpose of conducting a pre- and post-quantitative analysis. The findings are shown in Table 5. Examples of coded quotes are shown below.

$<<$ INSERT TABLE 5>>

Examples of (1) seeking out professional development opportunities are as follows:

- "Continuing to improve on my confidence and expanding my knowledge are a couple of ways I plan to improve."

- "Jot down topics of interest or importance and search for related information."

- "Keep taking challenging courses that push my limits." 
- "Subscribe to engineering newsletters as well as keeping in touch with the professors of Engineering 101 for answers and tips.”

Examples of (2) seeking out additional real-world projects are as follows:

- "I will use the skills and knowledge that I gained in this class in the real world when dealing with different clients."

- "I will look for projects related to [course] concepts we learned. Also, when possible, finding projects at my first job after college related to the material."

- "Continue to investigate ongoing problems in the world and see how engineers are fixing them."

- "Getting involved in outside projects or groups that try to improve or create new designs to help people in everyday life.”

Examples of (3) enrolling in additional engineering coursework are as follows:

- "I plan to continue studying engineering and one-day work in the field of engineering."

- "After this class is over I will further my skills/knowledge through my last semester of classes at [university] and then hopefully through the job I obtain after graduation."

- "I will continue to use the processes and tools I learned in this class into my capstone and future classes, job, or wherever I end up."

- "Whether in other [current courses] or maybe in my senior design courses. I hope I'll have opportunities to use this knowledge far beyond just this class."

Examples of (4) unsure are as follows:

- "This is a very vague question. I really do not know how to properly answer it."

- "I'm unsure at this point. I would likely look for future opportunity to apply what I have learned."

- "I honestly couldn't tell you."

\subsection{SQ 4: What did you like most about the online discussion component?}

In general, five themes arose to what students liked about the online discussion component: (1) interesting topics, (2) offered useful feedback and reflection, (3) allowed enough time to develop thoughts, (4) promoted critical thinking by extending class topics, and (5) did not like the online discussion component. All participant responses were coded as one of the five themes for the purpose of providing a quantitative summary. The findings are shown in Table 6. Examples of coded quotes are shown below.

\section{$<<$ INSERT TABLE 6 $>>$}

Examples of (1) offered useful feedback and reflection are as follows:

- "Seeing people's response and seeing things from their perspective helped me understand problems from different eyes."

- "I liked the fact that this class literally forced me to reflect and look into things farther. It grew my curios manner to the point where if I see something I find interesting I do research then reflect on it without an assignment."

- "I got to see what my peer members thought and what their thought process what like 
through the way they had expressed. There wasn't any interruption through everyone's thoughts, so they were able to take their time to put their thoughts together in a descriptive manner."

- "It allowed you to benchmark yourself against other students, so if you had gotten behind in a subject it would be very clear very quickly."

Examples of (2) interesting topics are as follows:

- "It usually had to do with what our next project was on so we automatically had some background knowledge on the subject and had some research/articles to look at."

- "I liked learning new things about topics I did not know much of previously."

- "I also got to read some neat articles that I would have never read for my own interest."

Examples of (3) promoted critical thinking by extending class topics are as follows:

- "The online discussions have given us a sampling of what we would discuss in the next class, and that many of them were thought provoking and different from much of the classic engineering questions."

- "They challenged me to look further in depth to a topic."

- "I liked the uniqueness of the idea since I have never done anything like it before."

- "It made you think outside the box."

Examples of (4) allowed enough time to develop thoughts are as follows:

- "It allows me to [take] my time and collect my thoughts when answering. It also allows me to answer the prompts over a large time range than would be allowed in class."

- "Free to type about your opinion with no initial criticism."

- "The freedom to complete assignments on our schedule."

Examples of (5) other are as follows:

- "The variety of questions. I wish it was more open-ended/free."

- "Not much."

- "n/a"

- "The fact that class was once a week."

\subsection{SQ 5: What could be improved with the online discussion component?}

In general, four themes arose to what students thought could be improved with the online discussion component: (1) clear instructions and instructor feedback, (2) better scheduling of due dates, (3) more engaging discussion prompts, and (4) nothing to improve. All participant responses were coded as one of the four themes for the purpose of providing a quantitative summary. The findings are shown in Table 7. Examples of coded quotes are shown below.

$<<$ INSERT TABLE 7>>

Examples of (1) more engaging discussion prompts are as follows:

- " "I think the topics could be more in-line with current issues and innovations."

- "Some of the response prompts were at times not needed, or possibly a different response 
prompt could've worked better."

- "More interactive/engaging way to connect thoughts to peers. (Like having a discussion rather than separate response posts) Building off of each other's thoughts online with a chat rather than posts."

- "I think having more discussions linked to the real world, rather than internal characteristics and values, would generate more enjoyment and interest."

- "I think as the semester progressed, the discussions began feeling a little repetitive (read an article, respond with a few ideas, respond to your peers' responses). I think making the activities a little more dynamic and diverse could be effective.”

Examples of (2) clear instructions and instructor feedback are as follows:

- "We didn't receive much feedback and they took a long time for them to be graded so it was a little hard to tell if you were doing them well or not."

- "Discussion questions are too lengthy and confusing. They should be more straight forward so that [peers] can understand each other clearly when responding to discussions.”

- "A little bit more direction of where to lead our answers. Sometimes my group has widely different answers. Giving a bit more of instruction would shorten the scope."

- "It would be great if there were real feedback to the responses. I always tried to be thoughtful in my responses, but some students were not as intentional. Knowing that it was basically graded on completion didn't promote an effort-filled atmosphere.”

Examples of (3) better scheduling of due dates are as follows:

- "It would be helpful if you have the due dates in [the learning management system] correspond to the initial post rather than the response post because it caused me to miss one or two assignments. It's our responsibility to look at our assignments but it's misleading to have them due later in the week if the initial post is due at the beginning."

- "The discussions should have a reasonable due date and time, not 24 hours before class, especially since schedules vary from day to day for a week. The discussions should add to the weeks' assignments, not become another weekly task that students must complete separately."

- "It seemed like there were too many online discussions to complete on top of all other assignments."

- "I don't think students take it seriously and will respond to the discussion right before it is due. Maybe if the discussion was due the same night the class was held so students can respond with the class material still fresh in their mind.”

Examples of (4) nothing to improve are as follows:

- "I can honestly say the discussions had clear guidelines as well as sources to complete them. I have no complaints."

- "I think the online discussion component is good as it is. Responses and replies are a good way to initiate a conversation or discussion and foster thinking."

- "I don't think there is anything else I would do differently with the online discussion component."

- " "The online discussions were a fun and enriching experience. No improvement needed.” 


\section{Discussion}

The two research questions will be answered taking into consideration the five survey questions answered within the results section. To better prepare the readers for aligning the results to the discussion section, it is noteworthy to remind of the association between the research questions and survey questions, as shown in Table 2.

\subsection{RQ 1: How can online discussions be used to increase student empowerment towards self- regulated learning in undergraduate core engineering courses?}

The open-ended survey questions, \#1 (factors important for student learning) and \#3 (perceptions of blended learning), provided insight into the first research question. The findings from \#1, as shown in Table 3, suggest a positive change in self-regulated learning from pre- to post-survey. Although not statistically significant, there was a 5.5\% increase from pre-survey responses (62.5\%) to post-survey responses (68\%) of students identifying factors fully within the student's control. This provides a potential implication around student empowerment and self-regulated learning over time. Yet, it should be pointed out that more than $60 \%$ of students identified that top factors for learning and success are in their control in the pre-survey. This may be indicative of a student demography, where majority of the students are already self-regulated learners.

The findings from \#3, as shown in Table 5, provide two key takeaways. First, the majority of the participants (about two-thirds of the students) viewed professional development opportunities as a way to further their skills/knowledge after the class. This provides positive support for the perceived benefit of continuous professional learning. Second, although the changes from pre- to post-survey responses were not statistically significant, the $6 \%$ decrease in enrolling in additional engineering coursework and 5\% increase in seeking out additional real-world projects suggests that perhaps students become more dependent upon their own internal motivation and less dependent upon coursework. Additionally, the upswing in interests in real-world projects may also be an indicator of better connections between theory and applications achieved through online discussions. However, it is important to note the upper level students might also be more likely to respond this way if they were in their final semester on the verge of graduation. Future research should be conducted to tease out these particular implications.

\subsection{RQ 2: How can online discussions increase student engagement and enhance student perceptions of class participation?}

The open-ended survey questions, \#2 (perceptions of blended learning), \#4 (likes related to online discussions) and \#5 (dislikes related to online discussions), provided insight into the second research question. Findings from \#2, as shown in Table 4, suggest a more open-minded approach to the benefits of both blended learning and face-to-face learning. Although the change from preto post-survey responses were not statistically significant, there was a positive increase in respondents that had mixed feelings in that they saw benefits in both blended learning and faceto-face learning. This implies a potential increase in critical thinking related to situational based learning outcomes. However, given that this data was generalized as a group, instead of individual pre- to post-, we could not gauge individual student responses before and after the online discussion intervention. The combined percentage of students that either preferred blended 
learning or a mixed approach increased from $67.5 \%$ to $72 \%$. Regardless of the change, this indicates that overall most students see value in blended learning.

The quantitative findings from \#4, as shown in Table 6, provide a summary of the percentages associated with student responses. The number one thing students liked about the online discussion component is that it offered useful feedback and reflection (43\%). This is commensurate with the literature where it has been reported that feedback plays an important role in student perception of learning efficacy [30, 42].

The findings from \#5, as shown in Table 7, provide a summary of the percentages associated with student responses. The number one thing students thought could be improved is the use of more engaging discussion prompts (38\%), followed by clear instructions and instructor feedback (26\%). This clearly indicates the importance of thoughtful design and selection of appropriate strategies for the success of blended learning in a course. It is also worthwhile to look at the next two popular responses to this question. A quarter of students wanted clearer instruction and better feedback. This may indicate two things. First, feedback is critical, as also seen from \#4. Second, the longing for clearer instruction may also be a result of usually prescriptive and definitive nature of these core engineering courses, where the answer to a question is often either right or wrong. This definitive nature may prompt students to simply search for a "right answer" rather than an enriching discussion of ideas. The third popular response of better scheduling again points back to the importance of appropriate instructional design in blended learning.

It is interesting to note that while useful feedback was the most liked feature of online discussions (Table 6), it was also brought up as the second most important deficiency (Table 7). This apparent disconnect and mixed responses could be due to the inclusion of three different instructors, different prompt designs, rubric and grading expectations, and/or quality of the students in the different courses. All of these should be further tested and explored.

\section{Conclusions}

\subsection{Contributions}

In this paper, we sought to answer the following research questions:

- RQ 1: How can online discussions be used to increase student empowerment towards selfregulated learning in undergraduate core engineering courses?

- RQ 2: How can online discussions increase student engagement and enhance student perceptions of class participation?

This paper makes several contributions. First, it provides an example of how online discussion can be integrated into core, analytically-focused engineering courses. In addition, this approach provides pedagogical evidence of positive implications towards increased self-regulated learning and student empowerment. Second, it provides insights into what students across three different engineering disciplines like/dislike about online discussions. This information can be used by engineering faculty, and instructional designers alike, to develop learning experiences that meet the perceived needs of students. Finally, it makes the case of integrating authentic learning 
experiences into the engineering classroom because that provides students the opportunity to connect real-world with theoretical underpinnings, thereby preparing them better for the workforce. To the final point, this paper shows how integrating online discussions into core engineering courses, without sacrificing course content, can indeed have positive implications towards self-regulated learning and higher student engagement.

\subsection{Limitations and Future Research}

The study was primarily qualitative in nature, which provided a more in-depth and richer understanding of the phenomena. However, future research would benefit from a more quantitative approach integrating quantitative, explanatory analysis to explain the phenomena better. Also, future research would benefit from access to more extensive and more diverse engineering and technology classrooms and student demography. Along these lines, future research could assess the types of discussion prompts, clarity of direction, types of grading scheme, etc. to understand the level of engagement and quality of responses promoted through the online discussions themselves. Future research can also evaluate the types of courses applying the online discussion intervention to determine if some specific courses offer greater opportunities than others to promote the integration of writing and critical thinking. This could allow for an explanation about what prompts and/or courses are the most effective and offer the greatest amount of contribution towards student learning. Similarly, future studies could assess the impact of different levels of feedback and influence of grading policies to better understand best practices associated with implementing online discussions in the engineering classroom. Also, future research could provide greater understanding and analysis towards sub-themes which have the potential for considering more implicit best practices around online discussion deployment, such as importance of the teacher-student relationship and academic time management. Finally, although the focus of the study was on core courses in the engineering classroom, the researchers are confident that online discussions and reflection prompts would be successful outside of the engineering classroom. Thus, future research should consider the use of online discussions within natural science courses, social science courses, and agricultural courses, to name a few other disciplines.

\section{Acknowledgment}

This work was supported by a KEEN (Kern Entrepreneurial Engineering Network) award. KEEN's mission is as follows: "We are a national partnership of universities with the shared mission to graduate engineers with an entrepreneurial mindset so they can create personal, economic, and societal value through a lifetime of meaningful work.”

\section{Appendix A: Example Online Discussion Prompt: Civil Engineering Course (Seniors): Water Resources Planning and Management}

Learning Objective: Research and summarize the conflicts between two countries of a shared water resources.

Hook: Most rivers in the world eventually make their way to the ocean, but the Colorado River dries up 100 miles before it reaches the Gulf of Mexico. This is due to the large number of withdrawals, primarily irrigation, that take place upstream. Determining who can use water from 
the river, where, and when is a significant issue as it is a shared resource between the U.S and Mexican governments. Recently the Mexican and U.S. government reached an accord on shared water use of the Colorado river. The accord specifies reductions in water deliveries during a shortage, as well as increases in water deliveries during wet periods. The agreement also provides for Mexico to continue storing water in Lake Mead, near Las Vegas, helping to boost the reservoir's levels, which in the past few years have dropped to historic lows. The accord would also establish a "Binational Water Scarcity Contingency Plan," in which Mexico would join U.S. states in temporarily taking less water out of Lake Mead to reduce the risks of the reservoir reaching critical levels. All of these actions serve as examples of a compromised agreement to address critical water supply issues in this shared water resource.

Initial Prompt: On your own, research a shared water resource between two countries and find the water use agreement between the two, if there is one. Summarize the water agreement or lack thereof. Who uses the water? What are the primary uses of the shared water resource? What actions does one country want to prevent in the other?

Response Prompt: Respond to one of your classmates initial posts. How does this agreement compare to the one you summarized? Which country seems to have the most at risk in this conflict?

\section{Appendix B: Example Online Discussion Prompt: Electrical and Computer Engineering Course (Seniors): Embedded Systems Design}

Learning Objective: Synthesize information to identify trends in the use of wireless communication in embedded systems.

Hook: Wireless communication has developed a lot in the past 15 years or so. This development continues today. Different wireless communication technologies are used in a variety of embedded systems. For example, in the case of so-called internet of things (IoT) type of embedded systems, wireless communication is used a lot. One of the primary advantages of wireless technologies is the elimination of cumbersome wiring, which for most applications can significantly reduce costs (including deployment/installation costs).

Initial Prompt: Use the internet to find two different resources that describe the trends in innovation related to the use of wireless communication in embedded systems. Summarize your findings as a bulleted list. Propose an example of an embedded system application that could be improved or even enabled by "potential future wireless technologies"; this should be stated in just one sentence. Be sure to cite your sources.

Response Prompt: Respond to a peer's post. Explain if you agree or disagree with the peer's post summary.

\section{Appendix C: Example Online Discussion Prompt: Mechanical Engineering Course (Juniors): Fundamentals of Heat Transfer}

Learning Objective: Identify different modes of heat transfer found in real world. 
Preamble: Discussion prompts in this forum are meant to get you thinking about different factors that affect heat transfer in our daily lives - from different modes of heat transfer to material properties to cost and aesthetic of heat transfer related equipment and designs! You are not required to serially address each question in the prompt. The questions are supposed to provoke your thought process and discussion. The expectation is that your initial thread will convey your opinion based on your understanding of the topic informed by the resources available, and that your responses to others contribute to the discussion in substantive ways - asking questions, extending ideas and/or providing alternative perspectives.

Hook: No winter lasts forever... but as long as it lasts, we need a good heater. The heating system in your apartment complex has broken down in the middle of the winter! You have to either buy a room heater or use the hitherto-unused fireplace in your living room or come up with a novel idea of heating. The landlord has agreed to cover the cost of heating as long as you use a reasonable method. What do you think you should use for heating - the existing fireplace, a convection room heater, a radiant room heater, some sort of Diesel/natural gas/wood burning stove (there are lots of novel stoves out there), or something else altogether? Now consider pitching your preferred method to the landlord.

Initial Prompt: Create a new thread to convince your landlord with your choice. Try to structure your thread in a way that landlord finds it interesting (for example, maybe add a cool picture, or some cool statistics/infographics). Remember, you are trying to sell your idea to the landlord, so make the thread engaging. And beware - your thread should not be too long, it should take at most 3 to 5 minutes to read, otherwise the reader may lose interest! In your thread, identify the method and/or equipment that you want to use. List/suggest where/how you can buy/make this. If it is a standard store-bought item, maybe give a manufacturer/model number. Give at least three (you can give more) reasons, one of them must be a technical reason, others can be technical and/or social/economic/environmental/aesthetic/legal, etc. reasons. Apart from the minimum three reasons, also list the primary mode of heat transfer in your choice.

Response Prompt: Pick a peer's idea (you can respond to more than one, if you like) and put on the hat of the landlord. Now discuss why you do not prefer this tenant's heating method. Give at least two (you can give more) reasons, one of them must be a technical reason. Keep in mind there is no wrong choice just a difference in preference and priorities! Lastly, consider rating all the posts (initial posts or responses) in the forum you found novel/interesting/out-of-the-box/thoughtprovoking with an Up vote (click on the + sign near the title of the corresponding post).

\section{References}

[1] L. Bosman, K. Chelberg, and S. Fernhaber, "Introduction to engineering: a constructivistbased approach to encourage engagement and promote accessibility," Global Journal of Engineering Education vol. 19, pp. pp. 237-242, 2017.

[2] L. Bosman, "From Doing to Thinking: Developing the Entrepreneurial Mindset through Scaffold Assignments and Self-Regulated Learning Reflection," Open Education Studies, vol. 1, pp. 106-121, 2019.

[3] L. Bosman and P. Voglewede, "How can a faculty community of practice change classroom practices?," College Teaching, 2019. 
[4] L. B. Bosman, N. Duval-Couetil, B. Mayer, and P. McNamara, "Using Online Discussions to Develop the Entrepreneurial Mindset in Environmental Engineering Undergraduates: A Case Study," International Journal of Engineering Pedagogy, vol. 9, 2019.

[5] L. Bosman and S. Fernhaber, Teaching the entrepreneurial mindset to engineers. Switzerland: Springer International Publishing, 2018.

[6] L. Bosman and S. Fernhaber, "Applying Authentic Learning through Cultivation of the Entrepreneurial Mindset in the Engineering Classroom," Education Sciences, vol. 9, p. 7, 2019.

[7] S. Ambrose, M. Bridges, M. Lovett, M. DiPietro, and M. Norman, How Learning Works. Hoboken, NJ: Jossey-Bass, 2010.

[8] R. Hughes, "GENDER CONCEPTION AND THE CHILLY ROAD TO FEMALE UNDERGRADUATES'PERSISTENCE IN SCIENCE AND ENGINEERING FIELDS," Journal of Women and Minorities in Science and Engineering, vol. 18, 2012.

[9] M. Meyer and S. Marx, "Engineering dropouts: A qualitative examination of why undergraduates leave engineering," in Qualitative Research in STEM, ed: Routledge, 2016, pp. 155-184.

[10] American Society for Engineering Education, "Engineering by the Numbers: ASEE Retention and Time-to-Graduation Benchmarks for Undergraduate Engineering Schools, Departments and Programs. Washington, DC: Brian L. Yoder," 2016.

[11] J. Linsdell and T. Anagnos, "Motivating technical writing through study of the environment.(Author abstract)(Report)," Journal of Professional Issues in Engineering Education and Practice, vol. 137, p. 20, 2011.

[12] L. Bosman, B. Mayer, and P. McNamara, "Promoting entreprenuerially minded learning through online discussions - curriculum innovation: incorporating the Kern Engineering Entrepreneurial Network (KEEN) framework into online discussions," in American Society of Engineering Education, Columbus, OH, 2017.

[13] L. M. Patterson and V. Slinger-Friedman, "Writing in Undergraduate Geography Classes: Faculty Challenges and Rewards," Journal of Geography, vol. 111, pp. 184-193, 2012.

[14] S. Naqvi, "Challenges of Integrating Academic Sources in Assessed Assignments: A Case of Arab EFL Learners," in Arab World English Journal (AWEJ) Proceedings of 1st MEC TESOL Conference, 2018.

[15] B. P. Katz and E. Thoren, "WikiTextbooks: Designing Your Course around a Collaborative Writing Project," PRIMUS, vol. 24, pp. 574-593, 2014.

[16] T. Miyazoe and T. Anderson, "Learning Outcomes and Students' Perceptions of Online Writing: Simultaneous Implementation of a Forum, Blog, and Wiki in an EFL Blended Learning Setting," System: An International Journal of Educational Technology and Applied Linguistics, vol. 38, pp. 185-199, 2010.

[17] C. A. Cherrstrom, C. Raisor, and D. Fowler, "Student chemical engineering reflective ePortfolios: ChE student perceptions of learning from reflective ePortfolio creation," Chemical Engineering Education, vol. 49, pp. 157-166, 2015.

[18] A. S. C. Fernandes, "Writing to Learn Writing Skills--A Case Study," European Journal of Engineering Education, vol. 37, pp. 179-192, 2012.

[19] R. Fries, B. Cross, J. Zhou, and C. Verbais, "How Student Written Communication Skills Benefit during Participation in an Industry-Sponsored Civil Engineering Capstone Course," Advances in Engineering Education, vol. 6, p. r, 2017. 
[20] R. A. Calvo and R. A. Ellis, "Students' Conceptions of Tutor and Automated Feedback in Professional Writing," Journal of Engineering Education, vol. 99, pp. 427-438, 2010.

[21] A. V. Vazquez, K. McLoughlin, M. Sabbagh, A. C. Runkle, J. Simon, B. P. Coppola, and S. Pazicni, "Writing-to-Teach: A New Pedagogical Approach to Elicit Explanative Writing from Undergraduate Chemistry Students," Journal of Chemical Education, vol. 89, pp. 1025-1031, 2012.

[22] M. A. Vetter and M. J. Nunes, "Writing Theory for the Multimajor Professional Writing Course: Writing Theory for the A Case Study and Course Design," Pedagogy, vol. 18, pp. 157-173, 2018.

[23] B. Duchardt, P. Furr, and S. Horton, "A Comparison of a Progression of Writing Competencies in Online Undergraduate and Graduate Courses: Results and Implications," College Student Journal, vol. 50, pp. 467-476, 2016.

[24] H. Idrus, A. M. Noor, and M. N. R. Baharom, "Motivating engineering and technical students to learn technical writing by inculcating lifelong learning skills," International Journal of Learning, vol. 18, pp. 191-202, 2012.

[25] T. Yakhno and E. Ekin, "Student Conference as a Student Centred Environment for Integrating Technical Writings into Computer Engineering Curriculum," Egit. Arast., vol. 11, pp. 259-272, 2011.

[26] J. Leydon, K. Wilson, and C. Boyd, "Improving Student Writing Abilities in Geography: Examining the Benefits of Criterion-Based Assessment and Detailed Feedback," Journal of Geography, vol. 113, 2014.

[27] S. W. Bonham, K. Jones, B. Luna, and L. Pauley, "An Integrated Model for Teaching Writing in the Introductory Laboratory.(RESEARCH and TEACHING)," Journal of College Science Teaching, vol. 48, p. 40, 2018.

[28] D. R. Garrison and H. Kanuka, "Blended learning: Uncovering its transformative potential in higher education," The internet and higher education, vol. 7, pp. 95-105, 2004.

[29] C. C. Chen and K. T. Jones, "Blended learning vs. traditional classroom settings: Assessing effectiveness and student perceptions in an MBA accounting course," Journal of educators online, vol. 4, p. n1, 2007.

[30] H.-J. So and T. A. Brush, "Student perceptions of collaborative learning, social presence and satisfaction in a blended learning environment: Relationships and critical factors," Computers \& education, vol. 51, pp. 318-336, 2008.

[31] J. S. Drysdale, C. R. Graham, K. J. Spring, and L. R. Halverson, "An analysis of research trends in dissertations and theses studying blended learning," The Internet and Higher Education, vol. 17, pp. 90-100, 2013.

[32] B. Güzer and H. Caner, "The past, present and future of blended learning: an in depth analysis of literature," Procedia-social and behavioral sciences, vol. 116, pp. 4596-4603, 2014.

[33] M. H. Cooney, P. Gupton, and M. O’Laughlin, "Blurring the lines of play and work to create blended classroom learning experiences," Early Childhood Education Journal, vol. 27, pp. 165-171, 2000.

[34] J. Beaver, B. Hallar, and L. Westmaas, "Blended Learning: Defining Models and Examining Conditions to Support Implementation," PERC Research Brief. Philadelphia: Research for Action, 2014. 
[35] B. Parsad, L. Lewis, and P. Tice, Distance education at degree-granting postsecondary institutions: 2006-2007: National Center for Education Statistics, Institute of Education Sciences ..., 2008.

[36] E. Voci and K. Young, "Blended learning working in a leadership development programme," Industrial and commercial training, vol. 33, pp. 157-161, 2001.

[37] C. J. Bonk, T. M. Olson, R. A. Wisher, and K. L. Orvis, "Learning from focus groups: An examination of blended learning," International Journal of E-Learning \& Distance Education/Revue internationale du e-learning et la formation à distance, vol. 17, pp. 97118, 2002.

[38] B. F. Melton, H. W. Bland, and J. Chopak-Foss, "Achievement and satisfaction in blended learning versus traditional general health course designs," International Journal for the Scholarship of Teaching and Learning, vol. 3, p. 26, 2009.

[39] O. Delialioglu and Z. Yildirim, "Design and development of a technology enhanced hybrid instruction based on MOLTA model: Its effectiveness in comparison to traditional instruction," Computers \& Education, vol. 51, pp. 474-483, 2008.

[40] V. Woltering, A. Herrler, K. Spitzer, and C. Spreckelsen, "Blended learning positively affects students' satisfaction and the role of the tutor in the problem-based learning process: results of a mixed-method evaluation," Advances in Health Sciences Education, vol. 14, p. 725, 2009.

[41] M. V. López-Pérez, M. C. Pérez-López, and L. Rodríguez-Ariza, "Blended learning in higher education: Students' perceptions and their relation to outcomes," Computers \& education, vol. 56, pp. 818-826, 2011.

[42] S. Vonderwell, "An examination of asynchronous communication experiences and perspectives of students in an online course: A case study," The Internet and higher education, vol. 6, pp. 77-90, 2003.

[43] M. Paechter and B. Maier, "Online or face-to-face? Students' experiences and preferences in e-learning," The internet and higher education, vol. 13, pp. 292-297, 2010.

[44] H. Khechine, S. Lakhal, D. Pascot, and A. Bytha, "UTAUT model for blended learning: The role of gender and age in the intention to use webinars," Interdisciplinary Journal of E-Learning and Learning Objects, vol. 10, pp. 33-52, 2014.

[45] S. Palmer and D. Holt, "Online discussion in engineering education: Student responses and learning outcomes," in Cases on online discussion and interaction: Experiences and outcomes, ed: IGI Global, 2010, pp. 105-122.

[46] P. Muñoz-Escalona and A. McLaren, "Online forums: A tool to enhance experimental engineering laboratories," International Journal of Mechanical Engineering Education, vol. 46, pp. 227-240, 2018.

[47] V. Braun and V. Clarke, "Using thematic analysis in psychology," Qualitative research in psychology, vol. 3, pp. 77-101, 2006.

[48] A. Corden and R. Sainsbury, Using verbatim quotations in reporting qualitative social research: researchers' views: University of York York, 2006.

[49] R. T. Osguthorpe and C. R. Graham, "Blended learning environments: Definitions and directions," Quarterly review of distance education, vol. 4, pp. 227-33, 2003. 